\title{
Aneurysmal Bone Cyst Plus In an 8 Year Old Female, A Case Report.
}

\author{
${ }^{1}$ Swapnil Moghe, ${ }^{2}$ Nitin Saini, ${ }^{3}$ Ajay Pillai, ${ }^{4}$ Anjali Moghe, ${ }^{5}$ Kavita Pillai \\ ${ }^{I}$ (Assistant Professor, Department of Oral \& Maxillofacial Surgery, Peoples Dental Academy, Bhopal, India) \\ ${ }_{2}^{2}$ (Assistant Professor, Department of Oral \& Maxillofacial Pathology, D.A.V (C) Dental college, Yamunanagar, \\ India) \\ ${ }_{3}^{3}$ (Associate Professor, Department of Oral \& Maxillofacial Surgery, Peoples Dental Academy, Bhopal, India) \\ ${ }^{4}$ (Lecturer, Department of Oral Medicine \& Radiology, Peoples Dental Academy, Bhopal, India) \\ 5 (Dental Surgeon, Bhopal, India)
}

Summary: Aneurysmal bone cyst $(A B C)$ is rare benign lesions of bone which are infrequent in craniofacial skeleton. $A B C$ 's are characterized by rapid growth pattern with resultant bony expansion and facial asymmetry. We describe a case of $A B C$ in a 08 year old Female patient affecting the right side of the anterior maxilla with expansion and thinning of the buccal \& palatal cortical plates. Treatment consisted of surgical curettage of the lesion. A one year follow- up showed restoration of facial symmetry and complete healing of the involved site.

\section{Background}

Aneurysmal bone cyst (ABC) has been recognized since 1893 when it was described as an ossifying hematoma by Van Arsdale ${ }^{1}$. Jaffe and Lichtenstein were the first to recognize $A B C$ as an intraosseous, osteolytic lesion, chiefly affecting the metaphyseal region of long bones and vertebrae. Bernier and Bhaskar described the first case of $\mathrm{ABC}$ in the jaws in $1958^{2,3}$. $\mathrm{ABC}$ is a benign cystic lesion of bone, composed of blood-filled spaces separated by connective tissue septa containing fibroblasts, osteoclast-type giant cells and reactive woven bone $e^{4}$. Fifty percent of $\mathrm{ABCs}$ arise in the long bones and $20 \%$ in the vertebral column. It accounts for $1.5 \%$ of the non odontogenic, nonepithelial cysts of the mandible ${ }^{1,5}$. It is found more frequently in the mandible than the maxilla (3:1) with preponderance for the body, ramus and angle of the mandible. It affects young persons under 20 years of age with no gender predilection ${ }^{5,6}$.

$\mathrm{ABC}$ can be classified into three types. Conventional or vascular type (95\%) manifests as a rapidly growing, expansive, destructive lesion causing cortical perforation and soft tissue invasion. The solid type (5\%) may present as a small asymptomatic lesion first noticed as radiolucency on a routine radiograph or as a small swelling ${ }^{7,8}$. A third form or mixed variant demonstrates features of both the vascular and solid types. It may be a transitory phase of the lesion because sudden activation or rapid enlargement of stable lesions has been reported $^{8}$.

\section{Case Presentation}

A 08 -year-old female patient reported to the Department of Oral and Maxillofacial Surgery with a complaint of an asymptomatic swelling in the right upper front teeth region since 2 months, which had gradually increased to the present size. Her medical and family history was unremarkable and there was a history of trauma. On extraoral examination, facial asymmetry was apparent with a diffuse swelling involving the right nasomaxillary region, measuring approximately $4 \times 5 \mathrm{~cm}$ as seen in figure 1 . The swelling was firm and nontender. Intraoral examination revealed a diffuse swelling in relation to right front teeth with vestibular obliteration as seen in figure $2 \& 3$. Egg shell crackling was present with partial extrution of 11 . Bluish swelling on anterior hard palate on right side was seen. On aspiration, blood-tinged fluid was obtained and electrical pulp testing showed that the involved teeth were non vital.

Orthopantomogram, occlusal radiograph of maxilla \& intraoral periapical radiograph shows well defined unilocular radiolucent area involving 11,12,53,54 \& erupting 14. Displacement of involved teeth is seen. Pathological root resorption is seen i.r.t 53 as seen in figure 4.

The surgical exposure of the lesion is shown in figure 5. The cystic content was excised in toto, along with extraction of offending tooth. Soft tissue specimen brownish in color, measuring about $2.8 \times 2.6 \times 1.4 \mathrm{cms}$, was firm in consistency. Cut surface shows micro- cavities in centre filled with brownish fluid. Tissue is grossly encapsulated as seen in figure $6 \& 7$.

$\mathrm{H} \& \mathrm{E}$ stained section shows large blood filled cystic spaces of varying sizes, surrounded by connective tissue comprising of osteogenic \& spindle shaped fibrogenic flattened mesenchymal cells. Cellular osteoid \& 
many multinucleated osteoclast like giant cells are seen in a predominantly cellular stroma. Focal areas showing myxoid changes \& erythrocytes spilled in the connective tissue as seen in figure 8 .

\section{Investigations}

1. Orthopantomogram

2. IOPA

3. Occlusal

4. Complete blood count $(\mathrm{CBC})$

5. Incisional biopsy done.

\section{Differential Diagnosis}

Differential diagnosis included eosinophilic granuloma, giant cell tumor, nonossifying fibroma, unicameral bone cyst, fibrous dysplasia, chondroblastoma, chondrosarcoma, chondromyxoid fibroma, Ewing's tumor, and, in older patients, metastatic carcinoma or myeloma. The lesions are often eccentric and irregular in structure and sometimes show calcification in the central areas. As a rule, the cortex is thin, but there is rarely a cortical defect or a soft tissue mass.

\section{Treatment}

Treatment of $\mathrm{ABC}$ is usually directed toward complete removal of the lesion. This may prove difficult at times since the lesions are often multilocular and may be divided by multiple bony septae ${ }^{3}$. The treatment modalities are percutaneous sclerotherapy, diagnostic and therapeutic embolization, curettage, block resection and reconstruction, radiotherapy and systemic calcitonin therapy ${ }^{5}$.Self-healing cases have also been reported on long-term follow-up ${ }^{17}$.Several authors recommend immediate reconstruction of the defect with autogenous grafts in cases of esthetic deformity, high risk of fractures and loss of mandibular continuity ${ }^{1,6,15}$. Simple curettage is associated with high recurrence rates varying from 21 to 50\%. But Motamedi etal ${ }^{3}$ have reported that initial resection is not necessary and have not noted any recurrences following surgical curettage of mandibular lesions. The present case was treated by curettage and regularly monitored. There was no evidence of any residual lesion after 1 year of follow-up.

\section{Discussion}

The term "aneurysmatic" refers to the "blow-out" effect or expansion of the affected bone that appears in these types of lesions ${ }^{9}$. The $\mathrm{ABC}$ of the jaw is a psuedocyst lacking epithelial lining ${ }^{6,9}$. It comprises $5 \%$ of all the lesions of the cranial and maxillofacial bones ${ }^{3}$ and is most common in those regions of the skeleton where there is both a relatively high venous and marrow content. This explains the rarity of $\mathrm{ABC}$ in the skull bones, in which there is low venous pressure ${ }^{5}$.

The etiology of $\mathrm{ABC}$ is controversial. According to Steiner and Kantor, the $\mathrm{ABC}$ can develop as either a primary or secondary lesion associated with other bone diseases. Levy et al. had proposed that a history of trauma and subperiosteal hematoma formation is an essential factor in the development of ABC. Struthers and Shear have also concluded that $\mathrm{ABC}$ can occur as a secondary phenomenon in a pre-existing lesion and that central giant cell granuloma appears to be the most common of these lesions ${ }^{1}$. Tillman et al. have reported 95 cases with no history of trauma ${ }^{8}$. In the present case also, there was no history of trauma. Jaffe and Lichentenstein refer to alterations in local hemodynamics causing increased venous pressures and engorgement of the vascular bed in the transformed bone, leading to resorption, connective tissue replacement and osteoid formation ${ }^{1,8}$. Hernandez et al. classified ABC as primary and secondary. Primary could be congenital or acquired and could originate from pre-existing AV malformations. The congenital type is seen in children and young adults with no history of trauma, whereas the acquired type is found in adults with a history of trauma. The secondary type is postulated to be associated with degeneration of pre-existing lesions such as a cyst, tumor or fibrosseous lesion ${ }^{1}$. The two lesions could exist independently. Hence, ABC is considered as nonneoplastic, fibrodysplastic, noncystic bone entity ${ }^{1,10}$. In the present case as no history of trauma was reported, the etiology could be either due to alterations in local hemodynamics or degeneration of any pre-existing lesion at the involved site. Panoutsakopoulos et al. had described three cases of ABC with chromosomal anomalies, involving band $16 \mathrm{q} 22^{11}$. Familial incidence of $\mathrm{ABC}$ has also been reported in literature ${ }^{12,13,14}$.

$\mathrm{ABCs}$ are most commonly found in long bones and vertebral column; $1.9 \%$ are reported to occur in jaws. An unusual location for ABC, i.e., mandibular condyle and coronoid process has also been reported ${ }^{8,9,15}$. $\mathrm{ABC}$ is extremely variable in clinical presentation, ranging from a small, indolent, asymptomatic lesion to rapidly growing, expansile, destructive lesion causing pain, swelling, deformity, neurologic symptoms, pathologic fracture and perforation of the cortex ${ }^{3}$. 
The radiological features of $\mathrm{ABC}$ in the jaws are quite conflicting; the bone is expanded, appears cystic resembling a honeycomb or soap bubble and is eccentrically ballooned. There may be destruction or perforation of the cortex and a periosteal reaction may be evident ${ }^{6}$.It may appear radiolucent, radiopaque or mixed. In our case, a unilocular radiolucency causing expansion of the cortical plates and thinning of the palatal border of the maxilla with root resorption of the involved teeth was present. The diagnosis based on radiographic appearance is impossible because there are other lesions having similar radiographic appearance, such as ameloblastoma, myxoma, central giant cell granuloma, odontogenic cysts or central hemangiomas of the bone ${ }^{16}$.

Histologically, $\mathrm{ABC}$ consists of many sinusoidal blood-filled spaces set in a fibrous stroma, with multinucleated giant cells and osteoid. Hemosiderin is present in variable amounts and there is evidence of osteoid and bone formation. This description is characteristic of the "classic or vascular" form ${ }^{9}$.The histologic features in our case were consistent with the above-mentioned features. Solid form is the other histological type, which is a noncystic variant with solid gray-white tissue, hemorrhagic foci and abundant fibroblastic and fibrohistiocytic elements with osteoclast-like giant cells, osteoblastic differentiation areas with osteoid and calcifying fibromyxoid tissue. The mixed form demonstrates elements of both vascular and solid types ${ }^{9}$.

There was no evidence of any residual lesion after 1 year of follow-up.

\section{Conclusion}

As the radiological features of $\mathrm{ABC}$ are varied, resembling many lesions, histopathologic analysis is a must for the diagnosis.

\section{Acknowledgment}

The authors would like to thank Dr. Kiran Desai for his constant encouragement \& support .

\section{Learning Points/Take Home Messages}

1. The radiological features of $\mathrm{ABC}$ in the jaws are quite conflicting; the bone is expanded, appears cystic resembling a honeycomb or soap bubble and is eccentrically ballooned. Hence $\mathrm{ABC}$ should be correlated histopathologically.

2. The use of histological markers is useful in reaching to a diagnosis of $\mathrm{ABC}$.

\section{References}

[1]. Gadre KS, Zubairy RA. Aneurysmal bone cyst of the mandibular condyle: Report of a case. J Oral Maxillofac Surg 2000; 58:43943.

[2]. Motamedi MH, Stavropoulos M.F. Large radiolucent lesion of the mandibular condyle. J Oral Maxillofac Surg 1997; 55:1300-4.

[3]. Kalantar Motamedi MH. Aneurysmal bone cyst of the jaws: Clinicopathological features, radiographic evaluation and treatment analysis of 17 cases. J Craniomaxillofac Surg 1998; 26:56-62.

[4]. Rosenberg AE, Nielsen GP, Fletcher JA. In: World Health Organisation Classification of tumours. Pathology and Genetics of Tumours of Soft tissues and Bone. Lyon: IARC Press; 2002. p. 338

[5]. Goyal A, TyagiI, Syal R, Agrawal T, Jain M. Primary aneurismal bone cyst of coronoid process. BMC Ear Nose Throat Disord 2006; 6:4.

[6]. Kiattavorncharoen S, Joos U, Brinkschmidt C, Werkmeister R. Aneurysmal bone cyst of the mandible: A case report. Int J Oral Maxillofac Surg 2003; 32:419-22.

[7]. López-Arcas JM, Cebrián L, González J, Burgueño M. Aneurysmal bone cyst of the mandible: Case presentation and review of the literatura. Med Oral Patol Oral Cir Bucal 2007; 12:401-3.

[8]. Pelo S, Gasparini G, Boniello R, Moro A, Amoroso PF. Aneurysmal bone cyst located in the mandibular condyle. Head Face Med 2009; 5:8.

[9]. Capote-Moreno A, Acero J, García-Recuero I, Ruiz J, Serrano R, de Paz V. Giant aneurysmal bone cyst of the mandible with unusual presentation. Med Oral Patol Oral Cir Bucal 2009; 14:E137-40.

[10]. Eisenbud L, Attie J, Garlick J, Platt N. Aneurysmal bone cyst of the mandible. Oral Surg Oral Med Oral Pathol 1987; 64:202-6. ^

[11]. Panoutsakopoulos G, Pandis N, Kyriazoglou I, Gustafson P, Mertens F, Mandahl N. Recurrent t(16; 17)(q22; p13) in aneurismal bone cysts. Genes Chromosom Cancer 1999; 26:265-6.

[12]. Vicenzi G. Familial incidence in two cases of aneurysmal bone cyst. Ital J Orthop Traumatol 1981; 7:251-3.

[13]. Power RA, Robbins PD, Wood DJ. Aneurysmal bone cyst in monozygotic twins: A case report. J Bone Joint Surg Br 1996; 78:3234.

[14]. Leithner A, Windhager R, Kainberger F, Lang S. A case of aneurysmal bone cyst in father and son. Eur J Radiol 1998; 29:28-30.

[15]. Martins WD, Fávaro DM. Aneurysmal bone cyst of the coronoid process of the mandible: A case report. J Contemp Dent Pract $2005 ; 6: 130-8$

[16]. Karabouta I, Tsodoulos S, Trigonidis G. Extensive aneurysmal bone cyst of the mandible: Surgical resection and immediate reconstruction. Oral Surg Oral Med Oral Pathol 1991; 71:148-50.

[17]. Malghem J, Maldague B, Esselinck XW, Noel H, De Nayer P, Vincent A. Spontaneous healing of aneurysmal bone cysts: A report of three cases. J Bone Joint Surg Br 1989; 71:645-50. 


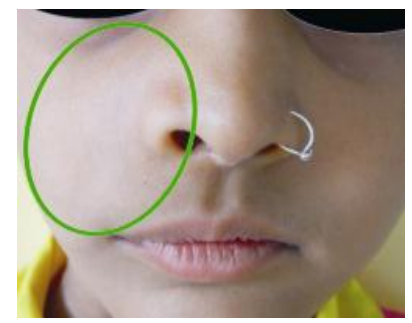

Figure 1: Diffuse swelling involving right side of face

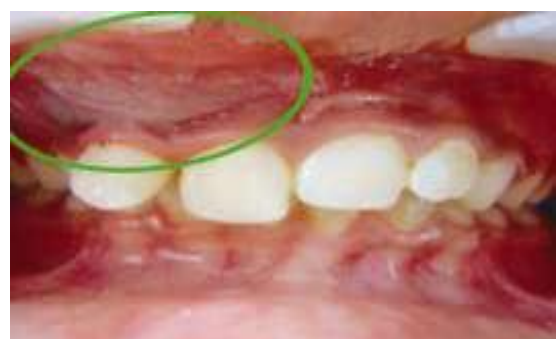

Figure 2: Vestibular obliteration on buccal aspect.

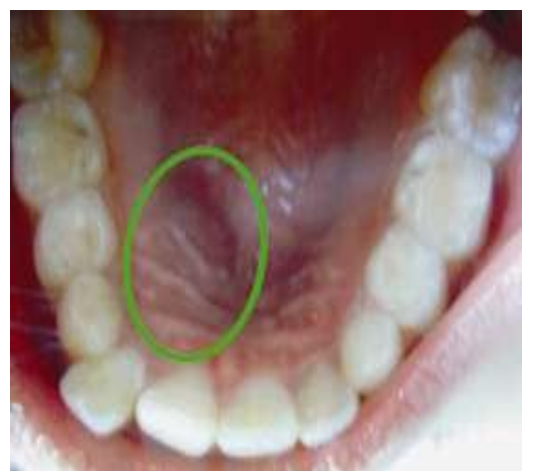

Figure 3: Vestibular obliteration on palatal aspect.

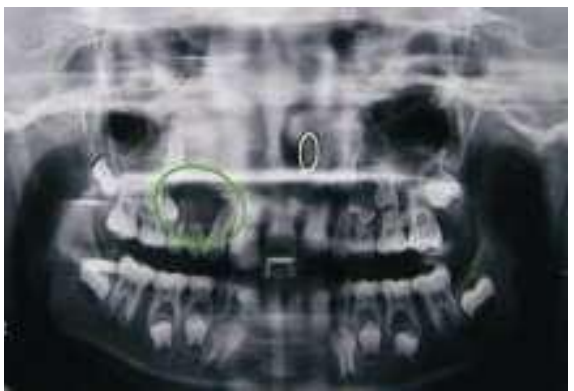

Figure 4: OPG Shows pathological root resorption with 53. 


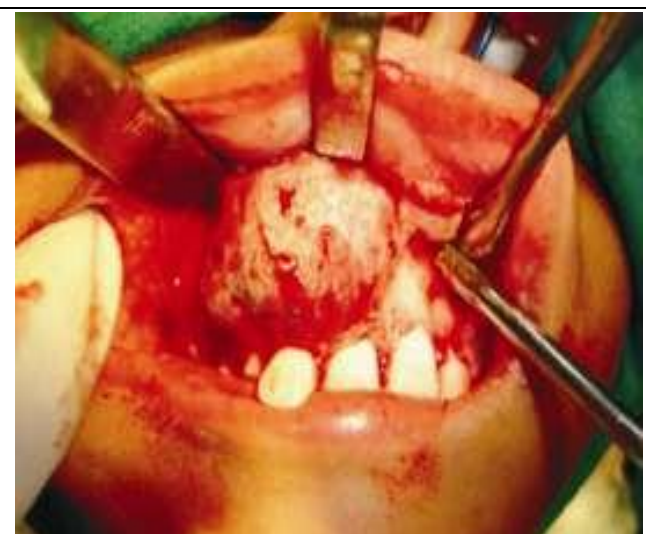

Figure 5: Surgical exposure of the lesion.

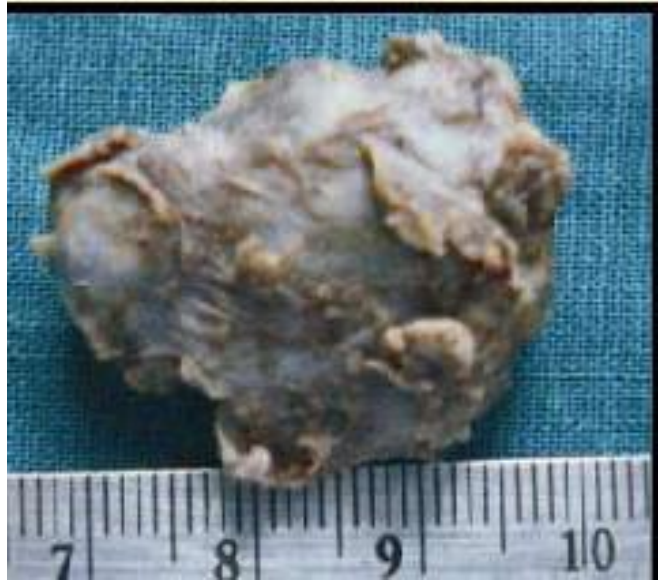

Figure 6: Soft tissue specimen brownish in color, measuring about 2.8 x 2.6 x $1.4 \mathrm{cms}$.

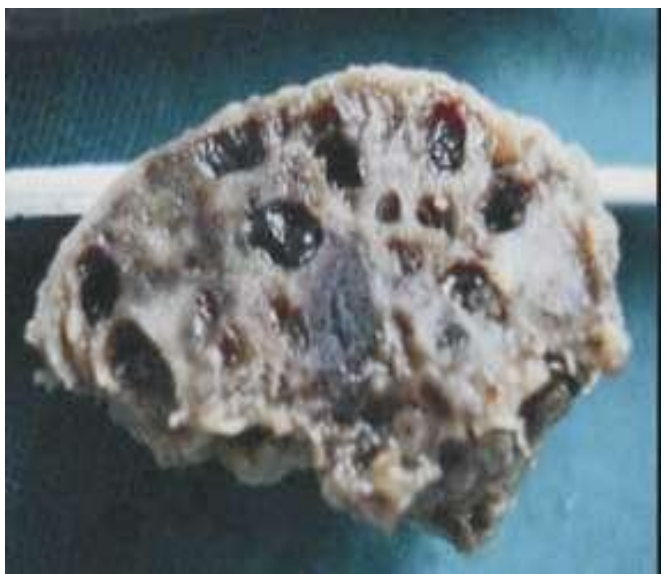

Figure 7: Cut surface shows micro- cavities in centre filled with brownish fluid. 


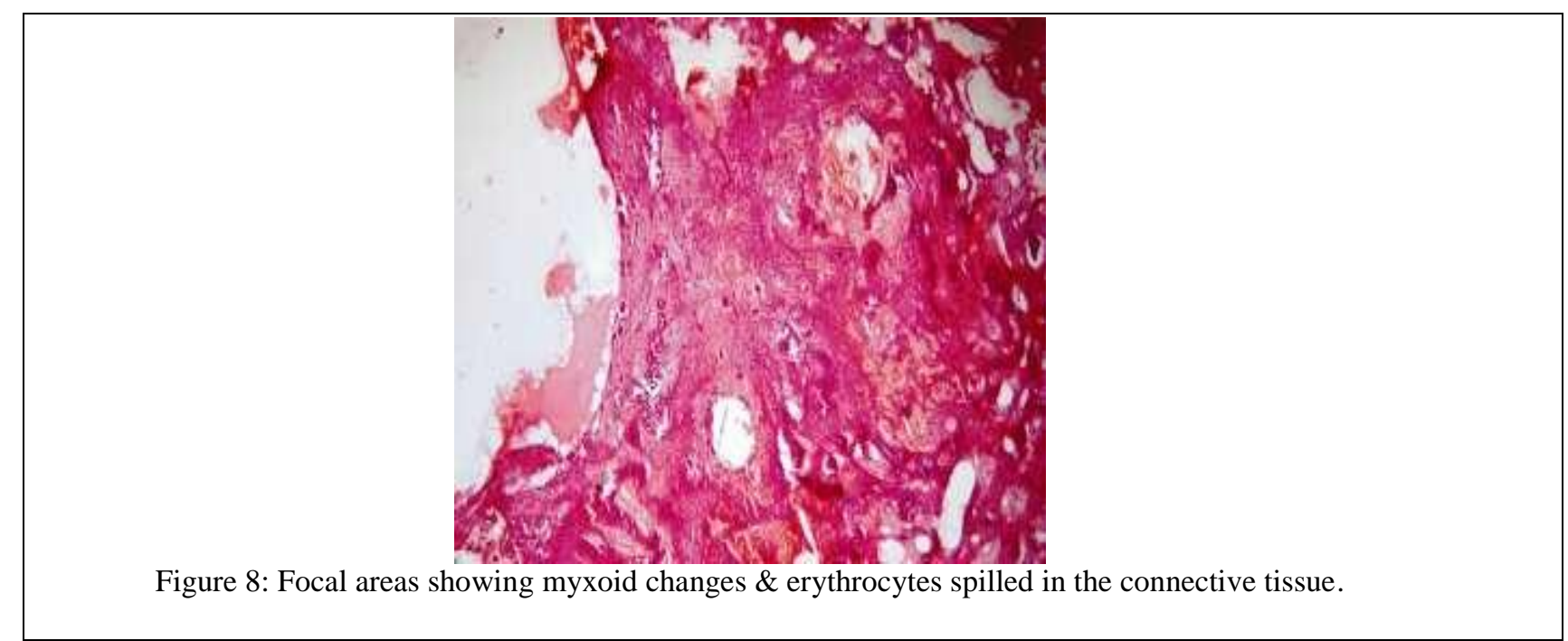

